ISBN 978-93-84468-86-6

2016 International Research Conference on Social Sciences, Humanities and Interdisciplinary Studies

(RCSSHIS-2016)

Pattaya (Thailand) Dec. 16-17, 2016

\title{
Community Outreach through the Use of Sport
}

\author{
Eoin J. Trolan \\ Hankuk University of Foreign Studies, Korea
}

\begin{abstract}
Sport has been a part of local communities for centuries particularly with spectators and participants at both amateur and professional levels. Recently though sport clubs become more socially aware and have embraced the concept of social responsibility. Particularly at the international and professional levels the public has seen an explosion of clubs or organizations embrace social responsibility. What I believe to be just as important, if not more important, is the social responsibility at the local level. Sport can and often does bring communities together when there is little common ground. In this paper, I will introduce a local organization that was recently founded on bringing communities together and promoting important social issues. The foundation is called the Live Life Lisa Orsi foundation and it was started in 2016 to remember a local sports player and travel enthusiast who passed away in 2015. This foundation has the objectives of promoting organ donation and in helping bridge two disenfranchised communities in the City of Derry, Northern Ireland. Thus, this paper will highlight the significance of using sport as a vehicle for social issues and a bridge at the local community level.
\end{abstract}

Keywords: Outreach, Inclusion, Sport, and Community

\section{Introduction}

"Sport has the power to change the world. It has the power to inspire. It has the power to unite people in a way that little else does. It speaks to youth in a language they understand. Sport can create hope where once there was only despair.

"It is more powerful than government in breaking down racial barriers. It laughs in the face of all kinds of discrimination." - Nelson Mandela, May 25, 2000

The above quote is much more than just about racial barriers but an insight into the considerable potential that sport can have on the development of society and of people. The level of investment and interest in utilizing sport as a vehicle for development has grown immensely over the past few decades and in fact many Governments such as the United States of America (US), United Kingdom (UK), Canada, and Australia utilize sport as a form of soft power or as a vehicle for social development (Giulianotti, 2011; Giulianotti \& Armstrong, 2011; Darnell, 2012). Indeed, these Governments, according to their own websites, spend millions of dollars or pounds in promoting sport and development. Additionally, these Governments also use professional sports stars to be the "face" for many development campaigns and these "sports ambassadors" bring an vast amount of goodwill to the providing country and participants. As such, the use of sport to enhance community development and social inclusion has been at the forefront of many professional sports organizations and governmental organizations. There are many professional teams, especially in the US, who are highly involved in community outreach through many different programs. Teams from the major sports such as National Football league, Major League Baseball, and National Basketball Association all contribute to community development (Babiak, Mills, Tainsky, Juravich 2012).

This work a was supported by Hankuk University of Foreign Studies Research Fund of 2016 
One term discussed by Babiak et al. (2012) and many other researchers use as a 'catch all' for this activity is corporate social responsibility or CSR. CSR in sports has now become an important component of any social platform for those teams because such organizations have advantages such as emotional connections with communities compared with many regular businesses. Whether it is in North America through the "Big 4" or in Europe through football and rugby, sporting organizations community outreach is now extremely valued. For example in Europe, the English Premier League and Scottish Premier League are heavily involved in CSR, though it is in its infancy when compared to the US. Teams in all the USA leagues have programs designed to help them become more involved in the communities where they play games and to help individuals within those communities. Furthermore, many individual players from these teams also have foundations in order to give back to the communities where they grew up or where they live. CSR while valuable does not explain fully why many amateur sports organizations participate within the community or why local foundations or organizations spend immense amount of time and energy in creating bridges within their communities. These local foundations and organizations are for the most part manned by volunteers and Putnam (2000) has stated such organizations have massive potential for strengthening communities and enhancing life skills. The sports industry according to Green and Oakley (2001) and Garrett (2004) highlighted that voluntary sports sector has a crucial role in community and sports development and regeneration.

Thus, this paper will examine a local sports community organization and highlight its impact and importance in the community and for the community in relation to personal and social development. This organization is called the Live Life Lisa Orsi Foundation (LLLO), which was founded to provide a community with a program that crossed cultures and promoted social issues. Therefore, its very inception through to its goals and future has been too focus on using sport to encourage community involvement and community action.

\section{Literature Review}

\subsection{CSR}

Carroll (1999) coined the term CSR and initially generally believed that CSR had economic benefits at the bottom and philanthropy at the top. More recently, researchers believe that CSR has now progressed into a more strategic philosophy rather than specific action. As a result, organizations now take a more proactive response to becoming involved in their local communities. The business community has embraced CSR on different levels and involved various stakeholders and as Mohr and Webb (2005) highlighted these organizations are involved in activities from non-profit organizations, environmental and human rights concerns. The use of CSR and these activities has allowed companies to become more strategically important within communities and enhance their competitiveness against other organizations (Brietbarth \& Harris, 2008). CSR does have a positive impact on how people value organizations and the amount of involvement that organizations have and how proactive they are all contribute to the overall success of CSR strategy. Thus, sport is ideal for community actives because of the connection with fans and the media. Indeed it can be a vehicle that is widely valued in society because it offers organizations easy access into communities at the local level.

\subsection{CSR and Sport}

The concept of giving back to the community has long been utilized by sports and CSR is a relatively new term that alludes to the idea of giving back to a community where the organizations are involved (Smith \& Westerbeek, 2007). The sport is one industry and an idea that can connect people from all areas of economic, social, and racial classes and as such provides the ideal tool for CSR. The use of sport has enormous potential for organizations. Sport organizations such as professional sport teams and organizations are now more socially responsible and socially aware. Thus, CSR offers these organizations the opportunity to have a positive impact in communities, while providing benefits to the organization.

This work a was supported by Hankuk University of Foreign Studies Research Fund of 2016 
The idea of sport assisting the community has been used to promote social integration, community development and outreach (Millington, 2010). The overall positive from using sport within the community is the engagement that it brings to people in tackling social and economical problems. Levermore (2008) reinforced this idea by underlining that sports can create awareness of many social ills through the actions of sport organizations in developing programs that are structured to attack obesity, poverty, disease, and to encourage education. Moreover, Coakley (2009) stated that sport has the power to change societies and communities for a positive if used properly. The potential to use sport to improve communities is possible because of the unique power that sport has to unite and captivate people and sport can be the main vehicle for local and community outreach and development.

\subsection{Community and Sport}

Sport can be a double-edged sword as there are negative and positive effects for both individuals and the community. Though the positives outweighs the negative effects in that overall using sport within the community can tackle social and economical problems. Therefore, it is important for organizations to focus on how to affect positive change within the communities they are involved in and to stress the benefits of such programs. As highlighted in the introduction there are many organizations that use sports to improve societal conditions. These programs have been well highlighted in the media and have been successful in improving many people's lives. While these organizations use sports to improve communities, it is governmental and NGO's who are at the forefront of tackling social problems internationally. One of the largest organizations to utilize sport for community outreach and development is the United Nations (UN). Huffman (2011) stressed that the UN's use of sport to build communities and its different programs through the United Nations Office on Sport for Development and peace (UNSDP) has been used to develop and bring success to local communities and individuals throughout the world. The programs deals with a wide variety of social issues and has contributing to a more peaceful society and a bridge that can allow for common ground.

In relation to this paper, the LLLO foundation is a non-profit organization similar to organizations such as 'football4peace' and 'right to play', which are two important organizations that contribute to improving society (Levermore, 2008). Like these organizations, LLLO has started small and is focused on the local areas to begin with. Of course sport itself cannot create change in isolation and as such it is important that organizations work with other organization and individuals to get the greatest level of benefits for the communities. Sports can and do allow organizations to gain an entrance into local communities and thus there are major benefits to using sport as a tool for outreach and development. Individuals can react and participate in sport whether they are experienced at sports people or are just beginners at sport. Indeed for many organizations that use sport as a tool for learning there are no restrictions in community sports games for development and outreach. Organizations and particularly organizations that use sport as their vehicle for change have a clear potential to promote their goals and objectives as well as developing and supporting local communities. Sport can empower disenfranchised communities and allow people to address such marginalization so that communities can begin to address mistrust and help forge lifelong bonding between people. The idea and concept that sport can be used as an excellent tool for achieving community and individual development or peaceful resolutions to disrupted regions is strengthened by members of international organizations and more importantly through real life practical examples such as the LLLO foundation.

\subsection{Case Study}

The LLLO Foundation was born out of a tragic death of a young woman in 2015. Lisa Orsi, originally, from the City Of Derry in Northern Ireland had traveled to Asia for work and to experience different cultures. Upon arriving in Asia, she participated in her local Gaelic sports club called the Singapore Gaelic Lions and became fully involved with Gaelic sports in Asia. She travelled all around Asia with the Singapore Gaelic Lions playing sports against other local Gaelic clubs. In late 2015, Lisa passed away due to an accident while hiking in This work a was supported by Hankuk University of Foreign Studies Research Fund of 2016 
Indonesia and in her short time in Asia made a huge impact on many people. After her accident, her family came to Asia to deal with the difficult task of having her body returned to Ireland and ensuring her organs were donated, as Lisa had wanted. The family had some difficulty in dealing with organ donation in Singapore due to bureaucracy but after several meetings they were able to have Lisa's organs arranged for donation. The strain of the bureaucracy entailed in ensuring a positive outcome in organ donation was one of the reasons why the foundation was started. When her parents arrived back in Ireland they developed the concept of an organization in her name to encourage people to embrace differences and to highlight the need for a worldwide promotion and structure in organ donation.

The foundations beginning had two objectives: 1) embrace diversity and challenges and 2) promote organ donation. The foundation objectives seemed simple but in Ireland and across the globe such objectives are never simple because of "red tape." In Ireland, just a simple act of playing sports can create a major issue due to long held historical divisions and community mistrust. Even today, we see people fleeing from trouble in regions in the Middle East and being marginalized and disenfranchised because they "look" different. Sport according to Amara, Aquilina, Argent, Betzer-Tayar, Green, Henry, Coalter, and Taylor (2004) can have a major impact in people's lives at all levels from physical and mental health, to personality development, and community and social integration. Sport can bring joy to people despite the dark surroundings.

As such, the LLLO foundation set forth a simple plan for the first year and that was to attempt to bring young people to visit Asia (in particular China) and to engage with the media to showcase community development and inclusion and to promote the social issue of organ donation. From the beginning of 2016, the volunteers from LLLO decided to bring 50 young people from the City of Derry to Asia to play in a Gaelic sports competition, to learn about different cultures, and to learn more about themselves as well. As the foundation was a new local based organization in Ireland they had no major governmental support but what they did have was enthusiastic volunteers and the young people travelling. They set about to raise the funds to travel and in just over nine months everyone involved had raised over 50,000 British pounds from the local community and local businesses. In that short period of time their dreams became a reality. The young people travelling to China were chosen from sporting clubs from their local communities and ranged from 17-21 years of age. The foundation wanted a mixture of people from all clubs and all ages who had never previously known each other and many had never travelled outside of Northern Ireland and had never experienced Asian culture. This desire was based in the belief that those travelling would have to learn to embrace differences and be open to those who were different to them.

For the months leading up to their trip the foundation embraced the idea of Chinese culture by learning about Confucianism and learning basic Mandarin from Chinese institutions in their local city. The foundation also embarked on many promotional activities in local and national papers. In an effort to promote their goals and objectives the foundation involved several local athletes and former athletes. One former athlete who was a major proponent of organ donation joined the foundation as an ambassador and having him involved garnered the foundation much needed support and media attention. Local and national newspapers became interested in why the foundation was set up, who was Lisa Orsi, and what did they hope to achieve. Additionally, the people travelling took part in many weekly events to raise funds and promote the foundation and these activities were very well highlighted on social media through Facebook and Instagram. Indeed, the publicity that the foundation received allowed the volunteers to easily reach their financial goal but more importantly had allowed them to promote its objectives to a nationally diverse audience and as such received interest from other sporting bodies and interested stakeholders for any future plans. The foundation through the hard work of its volunteers and its travelling party had achieved an immeasurable amount of public attention on their plans to travel and on their objectives and thus had achieved more success than they first believed could happen.

This work a was supported by Hankuk University of Foreign Studies Research Fund of 2016 


\section{Discussion}

The foundation, though started from grief, became an entity of delight in that people embraced life. From the very outset and conception of the idea - community youth development and promoting social issues were central to the goals and objectives of the foundation. Those involved were from the local community, those who sponsored the foundation were from the local community, and those who believed in its potential were from the local community. Thus, the foundation exceeded its initial motivation and has stimulated new local and national interest. The foundation succeeded in sending fifty people to attend the annual Asian Gaelic Games in Shanghai in 2016. They travelled to Beijing to experience Chinese history through visiting many historical and cultural sites. The traveling party made lifelong friends both from within their own party and from people who they met in Asia. Additionally, the support from the local and national newspapers has given the issue of organ donation new life and now when you think of sport volunteer organizations the LLLO foundation is well known even though it's still in its infancy. The issue of organ donation has once again become an important component in societal discussion and at the forefront of many peoples support

The question that must be asked is what is the next step to continue to achieve and promote the foundations goals. Two items must happen for it to become a fully established and sustainable community organization. The first is that after such a successful event, the foundation should explore and expand into cross community sports such as Rugby, Football, and Hockey. Gaelic sports are a traditionally Catholic sport while Rugby and Hockey are traditional Protestant sports (with football being mixed). As this trip focused on Gaelic sports, all the participants were Catholic and so the next trip away should be a mixed religious trip and thus reaching out to the "other" communities. This will allow young people from diverse racial and ethnic backgrounds to gain the same experience as the young people did this year. This concept is extremely important if the foundation is to become sustainable and embrace all sides of the local community. In Ireland, many communities are differentiated based on religion rather than race and likewise so are the sports. Therefore, embracing multiple sports will decrease this hostility. Similarly, to encourage growth with the local youth and to further promote social issues, the foundation should decide to attend a different continent every year to participate in a sports competition and learn about the local culture and history. There are many different sporting organizations around the world in all sports that would welcome the LLLO Foundation.

The second item that should happen to ensure stability and promotion of the foundations goals is a cross social issue platform. There are a plethora of social issues that communities in Ireland (and across the world) are facing from mental health, suicide awareness, physical health, social stigma, and body repatriation as the ultimate problem for affecting families and communities. One only needs to research these problems to find that they are consistently an issue no matter what country one lives in. Having different organizations work together to promote each other's social causes would create a positive relationship. The LLLO Foundation trip to China has shown that local communities can embrace differences and contribute to positive social change, thus, if such stakeholders would or could forge connections then visits such as LLLO going to China would bring in more potential press and therefore more attention to all relevant issues. This year in fact, there was a limited crossover between the LLLO and the Kevin Bell Repatriation Trust (KBRT), which helps repatriate the body of those who have died overseas originally from Ireland. This cross over was the beginning of a symbiotic relationship between LLLO and KBRT. I believe that such relationships with the other social issue organizations can only help all organizations - as the old saying goes 'a rising tide lifts all ships.'

Overall, the success of the trip to China and the Asian Gaelic Games has invigorated the foundation to strengthen its organization and to become more prominent in the local community as a vehicle for social inclusion and community development and outreach. Without doubt the experience that this trip has given the young people will remain with them for the rest of their lives and will impact them in many positive ways. The

This work a was supported by Hankuk University of Foreign Studies Research Fund of 2016 
next step is to embrace all members of the community across different demographics so that they too can experience cultures much different than their own and at the same time emphasize social change.

\section{Conclusion}

The foundation was created to remember a young lady who enjoyed sport, travel, diverse cultures, and social causes. From small beginnings, the foundation has amassed enormous support and respect from many in the local and national arena. In one year they have far surpassed what they had initially hoped for, in fact, from speaking with the foundation, they believe that they have created an organization that could lead from the front in terms of community outreach and stimulating social issues in Ireland and elsewhere. Leaders from communities that have long held resentment have began to soften their approaches to one another because the LLLO has shown that death, life, community and sport knows no boundaries and can affect all of us despite our differences. From the beginnings in grief, the foundation now epitomizes life and enjoyment. Fifty individuals travelled thousands of miles to participate in a cultural expedition and sport was used to encourage this adventure. The lessons learned from the foundations trip cannot be found in any book but only through personal experience and this experience would not have happened without sport. This is a perfect example of how sport, in this case Gaelic sports, can be used to bring people together and to promote community development and social issues that may otherwise have been unnoticed. Certainly, the foundation is an unyielding reminder of Lisa Orsi and to the need for stronger commitment to social issues, social inclusion, and community outreach. The Live Life Lisa Orsi foundation is now fully established organization that through the use of sports, can now bridge many communities divisions and at the same time promote important social issues.

\section{References}

[1] Amara, M., Aquilina, D., Argent, E., Betzer-Tayar, M., Green, M., Henry, I., Coalter, F., and Taylor, J. (2004). The Roles of Sport and Education in the Social Inclusion of Asylum Seekers and Refugees: An Evaluation of Policy and Practice in the UK. Institute of Sport and Leisure Policy Loughborough University: Stirling

[2] Babiak, K.B; Mills, B; Tainsky, S; Juravich, M. (2012). An Investigation Into Professional Athlete Philanthropy: Why Charity Is Part of the Game. Journal of Sport Management, 26, pp. 159-176 https://doi.org/10.1123/jsm.26.2.159

[3] Brietbarth, T., \& Harriss, P. (2008). The role of corporate social responsibility in the football business: Toward the development of a conceptual model. European Sport Marketing Quarterly, 8, 179-206. https://doi.org/10.1080/16184740802024484

[4] Carroll, A.B. (1999). Corporate social responsibility: Evolution of a definitional construct. Business \& Society, 38, 268-295. https://doi.org/10.1177/000765039903800303

[5] Coakley, J. (2009). Sports in society: Issues and controversies. New York, NY: McGraw-Hill.

[6] Darnell, S. (2012). Sport for Development and Peace: A critical sociology. London: Bloomsbury.

[7] Garrett, R. (2004) 'The response of voluntary sport clubs to Sport England's lottery funding: cases of compliance, change and resistance', Managing Leisure, Vol. 9, pp.13-29.

https://doi.org/10.1080/1360671042000182973

[8] Green, M. and Oakley, M. (2001) 'Elite sport development systems and playing to win: uniformity and diversity in international approaches', Leisure Studies, Vol. 20, pp.247-267.

https://doi.org/10.1080/02614360110103598

[9] Giulianotti, R. (2011). Sport, peace-making and conflict resolution: a contextual analysis and modeling of the sport, development and peace sector. Ethnic and Racial Studies, 34(2), 207-228. https://doi.org/10.1080/01419870.2010.522245

[10] Giulianotti, R. \& Armstrong, G. (2011). Sport, the Military and Peace making: History and possibilities. Third World Quarterly, 32(3), 379-394.

https://doi.org/10.1080/01436597.2011.573935

This work a was supported by Hankuk University of Foreign Studies Research Fund of 2016 
[11] Huffman, A. (2011). Using Sport to Build Community: Service-Learning with Iraqi Refugees. Unpublished Doctoral Dissertation, University of Tennessee, Knoxville.

[12] Levermore, R. (2008). Sport: a new engine of development? Progress in Development Studies, 8(2), 183-190. https://doi.org/10.1177/146499340700800204

[13] Millington, R. (2010). Basketball with (out) borders: Interrogating the intersections of sport, development, and capitalism. Unpublished Master Thesis. Queen's University, Ontario, Canada

[14] Mohr, A., \& Webb, D.J. (2005). The effects of corporate social responsibility and price on consumer responses. The Journal of Consumer Affairs, 39, 121-147. https://doi.org/10.1111/j.1745-6606.2005.00006.x

[15] Putnam, R. (2000) Bowling Alone: The Collapse and Revival of American Community, Simon and Schuster, New York.

https://doi.org/10.1145/358916.361990

[16] Smith, A., \& Westerbeek, H. (2007). Sport as a vehicle for deploying corporate social responsibility. Journal of Corporate Citizenship, 25, 43-54.

https://doi.org/10.9774/GLEAF.4700.2007.sp.00007 